\title{
Health-related quality of life in early-onset- scoliosis patients treated with growth- friendly implants is influenced by etiology, complication rate and ambulatory ability
}

Anna K. Hell ${ }^{1 *} \mathbb{D}$, Lena Braunschweig ${ }^{1}$, Jennifer Behrend ${ }^{1}$, Heiko M. Lorenz ${ }^{1}$, Konstantinos Tsaknakis ${ }^{1}$, Urs von Deimling ${ }^{2}$ and Kiril Mladenov ${ }^{3}$

\begin{abstract}
Background: Progressive Early-Onset Scoliosis (EOS) in children may lead to surgical interventions with growthfriendly implants, which require repeated lengthening procedures in order to allow adequate growth. Quality of life was studied using the validated German version of the EOS-Questionnaire (EOSQ-24-G) in surgically treated EOS children with different lengthening modalities.

Methods: EOSQ-24-G and the KINDL ${ }^{\mathrm{R}}$ questionnaire were given to families with EOS children who had been treated by either vertical expandable prosthetic titanium rib implants and repetitive lengthening surgeries every 6 months or children who had received a magnetically expansion controlled implant, which was externally lengthened every 3 months. Results were compared according to differences between the two tests, and with possible influencing factors such as surgical method, severity of scoliosis, relative improvement of curvature, etiology, weight, age, travelling distance, complications, ambulatory ability and others.

Results: 56 children with an average curve angle of $69^{\circ}$ corrected to $33^{\circ}$ (52\%; average age $\left.5.6 \mathrm{yrs}\right)$ answered the EOSQ-24-G and the KINDL ${ }^{R}$ after an average follow-up of 3.9 years. Health-related quality of life (HRQoL) was not affected by the initial scoliosis correction, the number of surgeries or the implant type. However, there was a negative correlation with non-ambulatory status, complications during treatment and for children with a neuromuscular scoliosis.

Conclusion: Using the validated EOSQ-24-G, no statistically significant differences were found between the group of children receiving repetitive surgeries and children with external lengthening procedures without surgery. However, results were influenced by the etiology, complication rate or ambulatory ability.
\end{abstract}

Level of Evidence/Clinical relevance: Therapeutic Level IV

Keywords: Health-related quality of life (HRQoL), Early-onset scoliosis questionnaire (EOSQ-24-G), Vertical expandable prosthetic titanium rib (VEPTR), Magnetic controlled growing rod (MCGR), Scoliosis, Influencing factors

\footnotetext{
* Correspondence: anna.hell@med.uni-goettingen.de

${ }^{1}$ Pediatric Orthopaedics; Department of Trauma, Orthopaedic and Plastic

Surgery, University Medical Center Goettingen, Goettingen, Germany

Full list of author information is available at the end of the article
}

(c) The Author(s). 2019 Open Access This article is distributed under the terms of the Creative Commons Attribution 4.0 International License (http://creativecommons.org/licenses/by/4.0/), which permits unrestricted use, distribution, and reproduction in any medium, provided you give appropriate credit to the original author(s) and the source, provide a link to the Creative Commons license, and indicate if changes were made. The Creative Commons Public Domain Dedication waiver (http://creativecommons.org/publicdomain/zero/1.0/) applies to the data made available in this article, unless otherwise stated. 


\section{Background}

Early-Onset Scoliosis (EOS) with progressive spinal deformity of various etiologies can cause severe and complex impairment of thoracic growth and pulmonary development well known as Thoracic Insufficiency Syndrome (TIS) and therefore often requires repetitive surgical treatment during childhood and adolescence [1]. In the last two decades, several growth-friendly spinal implant systems like vertical expandable prosthetic titanium rib (VEPTR) implants [1, 2], magnetically controlled devices (MCGR) [3, 4] and others have been developed to enable control of curve progression and spinal growth, to improve lung function and to enhance quality of life for the affected children and their families. However, the majority of these implants require repetitive surgeries during childhood correlating with implantrelated complications such as bacterial infections $[5,6]$, ossifications [7] or increased stiffness of the spine [8,9] as well as complications during surgery and psychological distress [10].

Success of scoliosis treatment is still often measured by means of radiological parameters including reduction of spinal deformity, a low complication rate and general health of the children. Recently, psychological factors have increasingly moved into the focus of treatment. Introduction of the comprehensive questionnaire EOSQ by Corona and colleagues in 2011 allows assessment of health-related quality of life (HRQoL) specific to the target patient population of EOS children and their families [11]. Since then, the EOSQ-24 has been translated and validated in various languages [12-16] and first studies have evaluated quality of life, family satisfaction and financial burden.

The aim of this study was to evaluate quality of life in relation to different demographic data like age, bodymass-index, etiology or distance to the medical center as well as therapy-related parameters such as type of implant (VEPTR versus MCGR), complication rate or ambulatory ability. Results of the validated German version of the EOSQ-24 [17] were compared to the generic $\mathrm{KINDL}^{\oplus}$ questionnaire for children [18].

\section{Methods}

After ethics committee approval, we conducted a crosssectional cohort study on 56 families with children diagnosed with EOS of any etiology and associated TIS in 2018. All participants were informed about the purpose of the study and oral and written consent was obtained. During a routine follow-up, care givers of the children were asked to complete the EOSQ-24-G, the validated German version of the EOSQ-24 [11, 17], and the $\mathrm{KINDL}^{\mathrm{R}}$ questionnaire, an internationally employed questionnaire for measuring the HRQoL of children without any diagnosis limitation [18]. The questionnaire was completed in the presence of a physician or the study nurse. Additionally, clinical data such as diagnosis, gender, type of treatment, age at surgical intervention, ability to walk and residence were obtained.

All participants were treated with a growth-friendly implant to control scoliotic curve progression. Vertical expandable prosthetic titanium rib (VEPTR) devices were implanted between the ribs and pelvis (bilateral) or ribs and lumbar spine (unilateral) with repetitive expansion surgeries approximately every six months. Magnetically controlled spinal implants (MCGR) were inserted bilateral using a VEPTR rib and pelvic fixation [19] and were expanded with an external remote controller every three months [19]. Exchange of the MCGR implants required surgery for these patients approximately every three years. After each lengthening procedure or surgical intervention, radiographs were taken and complications were documented.

Both questionnaires [17, 18] are parent-based and evaluate quality of life and burden of the disease in 24 items. Each item can be answered on a scale from one (not relevant) to five (very relevant). The score of each item was calculated as follows: averaged value of item choice -1$) / 4 * 100$. The mean of all 24 items is called the total score of quality of life, possibly ranging from 0 (poor) to 100 (excellent).

All obtained data including differences in HRQoL scores and impact of demographic data were analyzed statistically using Excel and if applicable with an analysis of variance (ANOVA) and post-hoc tests using the computer program Statistica 13.0 (Dell, USA). All data were presented as mean \pm standard deviation. Statistical significance was determined as $\left.p<0.05{ }^{(*)}\right), p<0.01\left(^{* *}\right)$ and as $p<0.001{ }^{(* * *)}$.

\section{Results}

\section{Patient demographics}

Fifty six patients (24 females, 32 males) who met the inclusion criteria of treatment of Early Onset Scoliosis (EOS) with growth-friendly implants were approached. The EOSQ-24 was completed by the caregivers of all 56 children, and 54 of them (96\%) also answered the KINDL $^{\mathrm{R}}$ questionnaire. Both questionnaires were returned with a minimum of missing data (below $2 \%$ ).

The participants' characteristics are summarized in Table 1 . The most common etiology was neuromuscular scoliosis $(n=31)$, followed by congenital scoliosis $(n=$ $13)$, syndromic scoliosis $(n=10)$ and idiopathic scoliosis $(n=2)$. Mean age at time of questionnaire was 9.2 years. At that time, all patients had undergone surgical implantation of VEPTR $(n=27)$ or MCGR $(n=29)$ devices, six patients of them had a conversion surgery from VEPTR to MCGR with their initial fixation anchors kept. Average time since implantation was 3.6 years (range 
Table 1 Overview of patient characteristics

\begin{tabular}{ll}
\hline Variable & Value \\
\hline Number of patients & 56 \\
Female & 24 \\
Male & 32 \\
Diagnosis & 31 \\
Neuromuscular & 13 \\
Congenital & 10 \\
Syndromic & 2 \\
Idiopathic & 27 \\
Type of implant & 29 \\
VEPTR & \\
MAGEC & \\
Therapy & 5.6 (0.9-13.1) \\
Average age at time of implantation in years (range) & $9.2(4.9-17.1)$ \\
Average age at time of questionnaire in years (range) & $9.9(2-25)$ \\
Number of lengthenings at time of questionnaire (range) & \\
\hline
\end{tabular}

0.5-9.0) with an average of 7.4 surgical lengthening procedures for the VEPTR patients and 10.7 outpatient lengthening procedures (plus 4.2 surgical extensions if VEPTR therapy was applied before) for the MCGR patients. Study subjects were also classified according to the distance of their residence to the medical center, which was on average $218 \mathrm{~km}$ driving distance (range $13-545 \mathrm{~km})$.

\section{Assessment of health-related quality of life (HRQoL)}

For all evaluated parameters, the EOSQ-24-G and the $\mathrm{KINDL}^{\mathrm{R}}$ questionnaire presented the same tendency. However, values for the $\mathrm{KINDL}^{\mathrm{R}}$ were throughout higher than the EOSQ-24-G values. The EOSQ-24-G total score averaged at 66 (range 30-98), whereas $\mathrm{KINDL}^{\mathrm{R}}$ showed an average total score of 76 (range 52-97).

Statistically, no difference could be found within the patient group regarding the following parameters: (1) sex, (2) age at time of implantation of a growth-friendly implant, (3) age at time of questionnaire completion, (4) weight, (5) type of implant, (6) distance to the medical center or (7) duration of therapy. Interestingly, also the severity of scoliosis and the relative improvement by the growth-friendly implant had no effect on subjective evaluation of quality of life. The mean scoliotic curve was $69^{\circ}$ before and $33^{\circ}$ directly after surgical implantation. At the time of questionnaire completion, scoliosis averaged at $39^{\circ}$ with the relative improvement ranging from 2 to $94 \%$.

The main etiology of the study group (55\%) was a neuromuscular scoliosis. These patients were compared to patients with other etiologies. Neuromuscular patients had lower total scores in quality of life than patients with congenital, syndromic or idiopathic scoliosis (EOSQ-24 $p=0.023$ KINDL $^{\mathrm{R}} p=0.555$ ) (Fig. 1).

Additionally, a negative correlation of non-ambulatory patients in comparison to walking patients was found (Fig. 2), probably reflecting the fact that neuromuscular children and non-ambulatory cases presented the same patient population.

The complication rate of our study group averaged at $48 \%$ and affected VEPTR $(n=13 / 27)$ and MCGR $(n=$ $14 / 29$ ) patients likewise. HRQoL of EOS patients and their families were influenced by the occurrence of complications (Fig. 3). Study participants who had no complications during their therapy with a growth-friendly implant (52\% of the total population) scored higher values than patients with at least one complication occurring during treatment (EOSQ-24 $p=0.020 ; \mathrm{KINDL}^{\mathrm{R}}$ $p=0.110)$.

\section{Discussion}

Children with progressive EOS and their families usually face several years of continuous treatment. Most implants require repetitive lengthening procedures either surgically or externally controlled. Surgical procedures are correlated with implant-related issues such as bacterial colonization [5, 6], ossifications [7] or increased stiffness of the spine $[8,9]$ as well as complications during surgery, intensive care visits and psychological distress [10]. After introduction of magnetically controlled implants (MCGR) [4], a significant improvement of HRQoL was expected mainly due to the decrease in the number of surgical interventions. Interestingly, this effect could not be found in our group as well as in other patient populations [20, 21]. Only Doany et al. [22] 

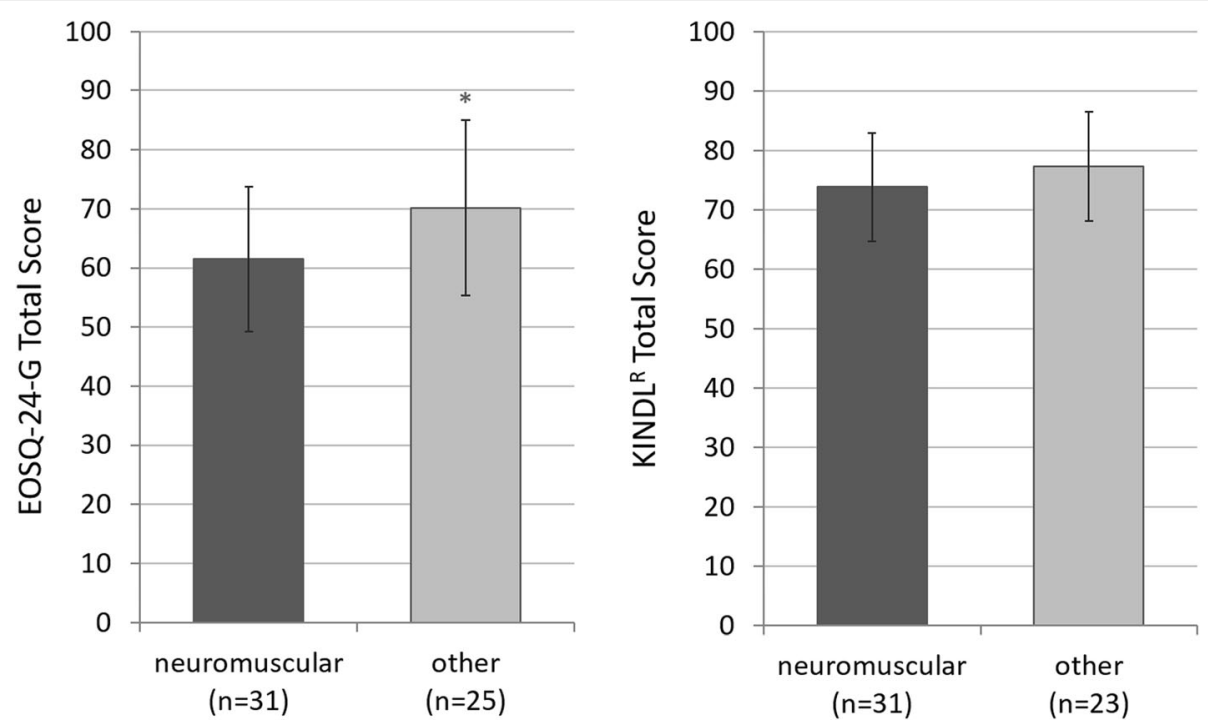

Fig. 1 EOSQ-24-G (left) and KINDL ${ }^{\oplus}$ (right) total score in quality of life measurement of patients with neuromuscular scoliosis compared to patients with other etiologies. The means \pm standard deviations are presented with statistical significance highlighted as * $p<0.05$

reported on better HRQoL results in MCGR patients, but with significantly shorter follow-up in the MCGR group in comparison to patients with traditional growing rod implants. Our data showed a significantly less favorable HRQoL in non-ambulatory and neuromuscular patients as well as in children with complications. Aslan et al. [21] stated no advantage of HRQoL in MCGR children if no major complications occurred. Therefore, psychological well-being rather seems related to an uneventful treatment course no matter how many surgeries are performed than the actual number of surgical interventions, which might be less in MCGR patients with complications than in the VEPTR or traditional growing rod population.

Neuromuscular scoliosis and non-ambulatory ability were also negatively correlated to the psychosocial status most likely reflecting the overall increased care effort of these families. Many of our children were suffering from Spinal Muscular Atrophy (SMA) and had additional non-invasive ventilation as well as nutrition issues. Therefore, these additional burdens may be reflected in the less favorable results.
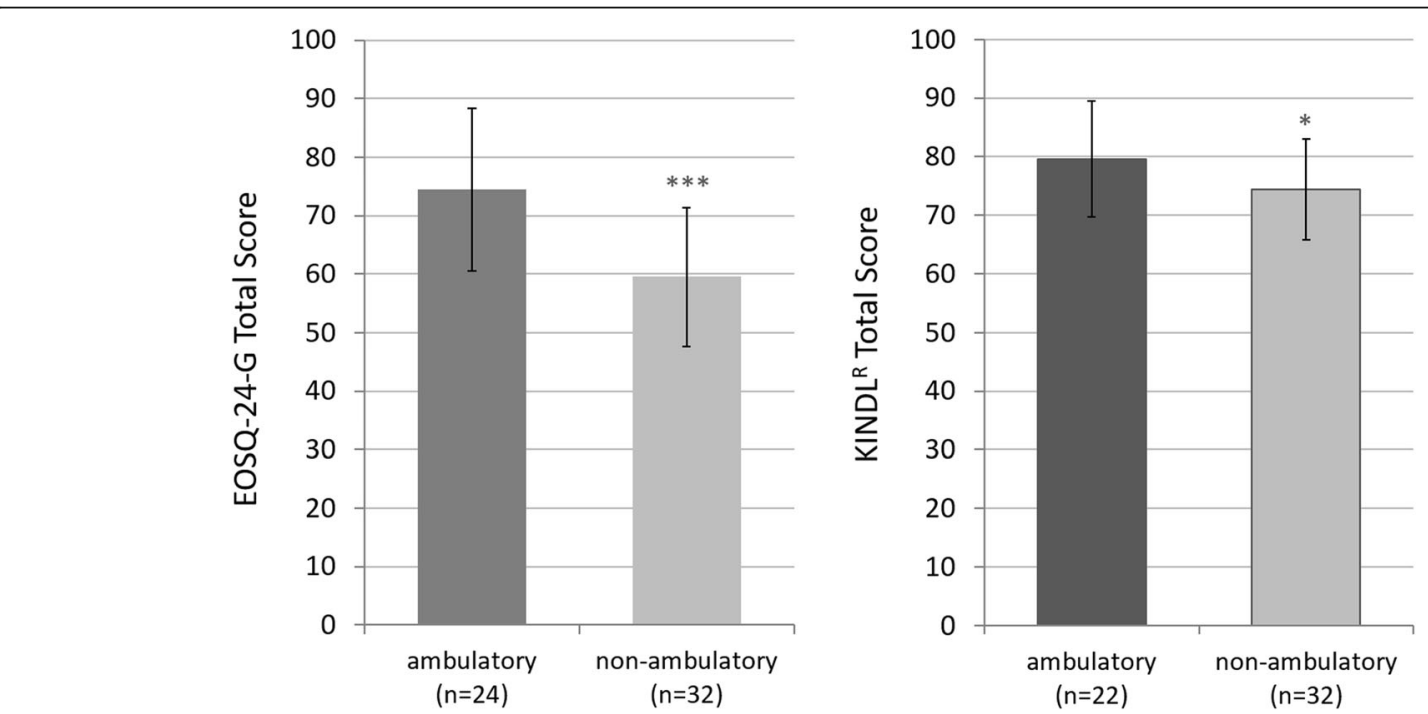

Fig. 2 EOSQ-24-G (left) and KINDL ${ }^{\circledast}$ (right) total score in quality of life measurement of ambulatory patients compared to non-ambulatory patients. The means \pm standard deviations are presented with statistical significance highlighted as ${ }^{* *} p<0.001,{ }^{*} p<0.05$ 

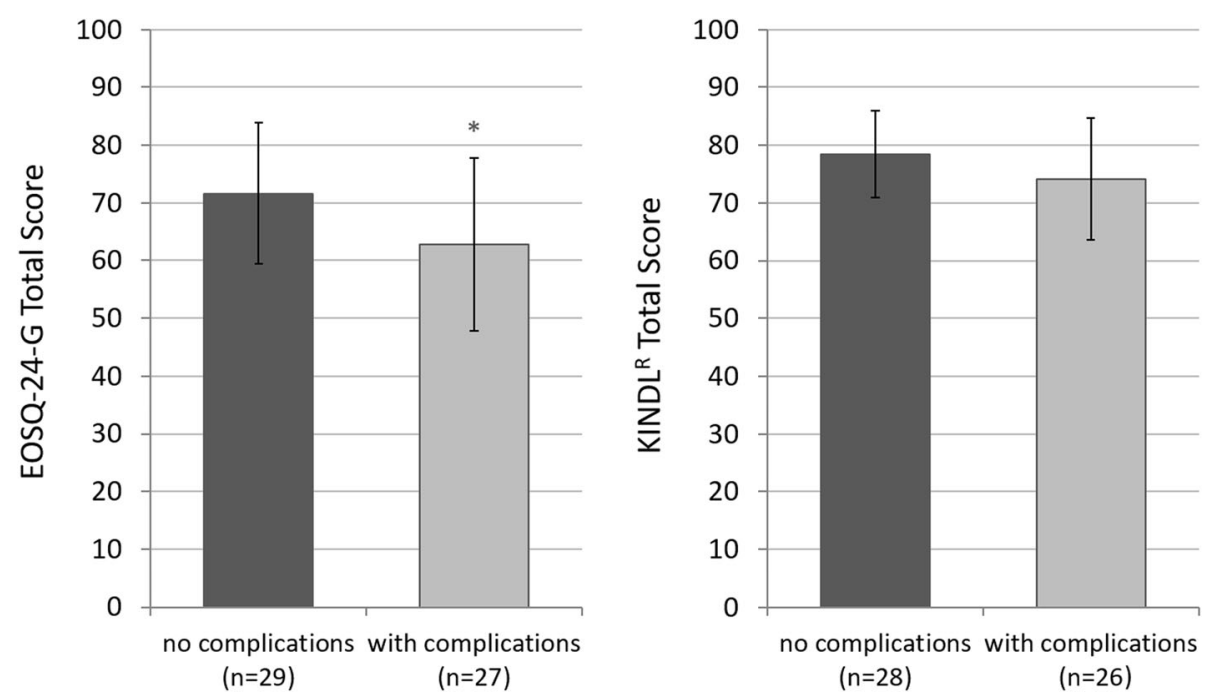

Fig. 3 EOSQ-24-G (left) and KINDL ${ }^{\oplus}$ (right) total score in quality of life measurement of patients without complications compared to patients with any complication during therapy. The means \pm standard deviations are presented with statistical significance highlighted as ${ }^{*} p<0.05$

In a previous publication [17], the German adaption of the EOSQ-24 (EOSQ-24-G) had shown an excellent reliability in comparison to other validated translations of the EOSQ-24. In this study the EOSQ-24-G was also compared to the $\mathrm{KINDL}^{\mathrm{R}}$ questionnaire, an internationally employed questionnaire for measuring the HRQoL of children without any diagnosis limitation [18]. Throughout our investigation, $\mathrm{KINDL}^{\mathrm{R}}$ results were higher in comparison to EOSQ-24-G values. There was no statistical difference in both tests, meaning that both questionnaires were able to obtain identical information but on a different score value. Heterogeneity at the questionnaire evaluation time as well as no baseline data before surgery are limitations of this study.

In summary, EOSQ-24-G data reviled no differences in psychosocial data in patients and family treated with MCGR and less surgeries in comparison to VEPTR treated children with repetitive surgical interventions. Patient satisfaction was rather dependent on complications during the treatment course and the additional medical problems as seen in neuromuscular children.

\section{Conclusion}

Health-related quality of life (HRQoL) was not dependent on the type of implant and therefore the number of surgeries. However, the etiology of neuromuscular scoliosis, complications during the therapy and non-ambulatory ability caused significant lower HRQoL values.

\section{Abbreviations}

ANOVA: Analysis of variance; EOS: Early-Onset Scoliosis; EOSQ-24: Early-Onset Scoliosis -Questionnaire; HRQoL: Health-related quality of life; MCGR: Magnetic Controlled Growing Rod; TIS: Thoracic Insufficiency Syndrome; VEPTR: Vertical Expandable Prosthetic Titanium Rib
Acknowledgements

Not applicable.

\section{Authors' contributions}

AKH and KM initiated the idea and design of the study. AKH, HML, KT, UvD and KM recruited participants. JB and KM acquired all questionnaires with the help of HML and KT. LB and JB were the major contributors in analysing the data and doing statistical analysis. AKH, LB and KM authored the initial draft. All authors gave final approval and agreed to be accountable for all aspects of the work.

Funding

No funding was obtained for this study.

\section{Availability of data and materials}

Please contact author for data requests.

\section{Ethics approval and consent to participate}

All procedures performed in studies involving human participants were in accordance with the ethical standards of the institutional and/or national research committee and with the 1964 Helsinki declaration and its later amendments or comparable ethical standards. All participants were informed about the purpose of the study and oral and written consent was obtained. In the cases of children under 16 years old, consent for participation was obtained from their parent or guardian. The Institutional Ethics Committee of University Medical Center Göttingen approved the study and waiver of written informed consent (reference number 21/9/17).

Consent for publication

Not applicable.

\section{Competing interests}

The authors declare that they have no competing interests.

\section{Author details}

'Pediatric Orthopaedics; Department of Trauma, Orthopaedic and Plastic Surgery, University Medical Center Goettingen, Goettingen, Germany.

${ }^{2}$ Department of Pediatric Orthopaedics; Asklepios, Sankt Augustin, Germany. ${ }^{3}$ Department of Pediatric Orthopaedics, Altonaer Children's Hospital,

Hamburg, Germany. 
Received: 13 August 2019 Accepted: 26 November 2019

Published online: 07 December 2019

\section{References}

1. Campbell RM, Smith MD, Mayes TC, Mangos JA, Willey-Courand DB, Kose N, et al. The characteristics of thoracic insufficiency syndrome associated with fused ribs and congenital scoliosis. J Bone Joint Surg Am. 2003;85-A:399408.

2. Campbell RM, Smith MD, Hell-Vocke AK. Expansion thoracoplasty: the surgical technique of opening-wedge thoracostomy. Surgical technique. J Bone Joint Surg Am. 2004;86-A(Suppl 1):51-64.

3. Akbarnia BA, Cheung K, Noordeen H, Elsebaie H, Yazici M, Dannawi Z, et al. Next generation of growth-sparing techniques: preliminary clinical results of a magnetically controlled growing rod in 14 patients with early-onset scoliosis. Spine. 2013;38:665-70.

4. Cheung KM-C, Cheung JP-Y, Samartzis D, Mak K-C, Wong Y-W, Cheung W-Y, et al. Magnetically controlled growing rods for severe spinal curvature in young children: a prospective case series. Lancet Lond Engl. 2012;379:196774.

5. Plaass C, Hasler CC, Heininger U, Studer D. Bacterial colonization of VEPTR implants under repeated expansions in children with severe early onset spinal deformities. Eur Spine J Off Publ Eur Spine Soc Eur Spinal Deform Soc Eur Sect Cerv Spine Res Soc. 2016;25:549-56.

6. Wagner L, Braunschweig L, Eiffert $H$, Tsaknakis K, Kamin D, D'Este E, et al. Detection of Bacteria colonizing titanium spinal implants in children. Surg Infect (Larchmt). 2018:19:71-7.

7. Groenefeld B, Hell AK. Ossifications after vertical expandable prosthetic titanium rib treatment in children with thoracic insufficiency syndrome and scoliosis. Spine. 2013;38:E819-23.

8. Sankar WN, Skaggs DL, Yazici M, Johnston CE, Shah SA, Javidan P, et al. Lengthening of dual growing rods and the law of diminishing returns. Spine. 2011;36:806-9.

9. Cahill PJ, Marvil S, Cuddihy L, Schutt C, Idema J, Clements DH, et al. Autofusion in the immature spine treated with growing rods. Spine. 2010; 35:E1199-203.

10. Flynn JM, Matsumoto H, Torres F, Ramirez N, Vitale MG. Psychological dysfunction in children who require repetitive surgery for early onset scoliosis. J Pediatr Orthop. 2012;32:594-9.

11. Corona J, Matsumoto $H$, Roye DP, Vitale MG. Measuring quality of life in children with early onset scoliosis: development and initial validation of the early onset scoliosis questionnaire. J Pediatr Orthop. 2011;31:180-5.

12. Del Mar P-BM, Matsumoto H, Vitale MG, Praena-Fernández JM, Farrington DM. Reliability and validity of the adapted Spanish version of the earlyonset Scoliosis-24 questionnaire. Spine. 2016:41:E625-31.

13. Demirkiran HG, Kinikli Gl, Olgun ZD, Kamaci S, Yavuz Y, Vitale MG, et al. Reliability and validity of the adapted Turkish version of the early-onset Scoliosis-24-item questionnaire (EOSQ-24). J Pediatr Orthop. 2015;35:804-9.

14. Molland RS, Diep LM, Brox JI, Stuge B, Holm I, Kibsgard TJ. Reliability and construct validity of the adapted Norwegian version of the early-onset scoliosis 24-item questionnaire. J Am Acad Orthop Surg Glob Res Rev. 2018; 2:e066.

15. Cheung JPY, Cheung PWH, Wong CKH, Samartzis D, Luk KD-K, Lam CLK, et al. Psychometric validation of the traditional Chinese version of the early onset Scoliosis-24 item questionnaire (EOSQ-24). Spine. 2016;41:E1460-9.

16. Hanbali $Y$, Perry $T$, Hanif A, Matsomotu H, Musmar H, Bader K, et al. Reliability and validity of the Arabic version of the early onset scoliosis 24 items questionnaire (EOSQ-24). SICOT-J. 2019;5:7.

17. Mladenov K, Braunschweig L, Behrend J, Lorenz HM, von Deimling U, Hell AK. Validation of the German version of the 24-item early-onset scoliosis questionnaire. J Neurosurg Pediatr. 2019;23:688-93.

18. Ravens-Sieberer $U$, Bullinger M. Assessing health-related quality of life in chronically ill children with the German KINDL: first psychometric and content analytical results. Qual Life Res Int J Qual Life Asp Treat Care Rehabil. 1998;7:399-407.

19. Hell AK, Groenefeld K, Tsaknakis K, Braunschweig L, Lorenz HM. Combining bilateral magnetically controlled implants inserted parallel to the spine with rib to pelvis fixation: surgical technique and early results. Clin Spine Surg. 2018:31:239-46.

20. Bekmez S, Afandiyev A, Dede O, Karaismailoğlu E, Demirkiran HG, Yazici M. Is magnetically controlled growing rod the game changer in early-onset scoliosis? A Preliminary Report. J Pediatr Orthop. 2019;39:e195-200.
21. Aslan C, Olgun ZD, Ayik G, Karaokur R, Ozusta S, Demirkiran GH, et al. Does decreased surgical stress really improve the psychosocial health of earlyonset scoliosis patients? A comparison of traditional growing rods and magnetically-controlled growing rods patients reveals disappointing results. Spine. 2019;44:E656-E663.

22. Doany ME, Olgun ZD, Kinikli Gl, Bekmez S, Kocyigit A, Demirkiran G, et al. Health-related quality of life in early-onset scoliosis patients treated surgically: EOSQ scores in traditional growing rod vs. magneticallycontrolled growing rods. Spine. 2018;43:148-53.

\section{Publisher's Note}

Springer Nature remains neutral with regard to jurisdictional claims in published maps and institutional affiliations.
Ready to submit your research? Choose BMC and benefit from:

- fast, convenient online submission

- thorough peer review by experienced researchers in your field

- rapid publication on acceptance

- support for research data, including large and complex data types

- gold Open Access which fosters wider collaboration and increased citations

- maximum visibility for your research: over $100 \mathrm{M}$ website views per year

At BMC, research is always in progress.

Learn more biomedcentral.com/submissions 